\title{
Preliminary study on microR-148a and microR-10a in dermal papilla cells of $\mathrm{Hu}$ sheep
}

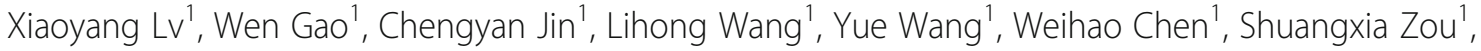 \\ Sainan Huang ${ }^{1}$, Zhifeng $\mathrm{Li}^{1}$, Jinyu Wang ${ }^{1 *}$ and Wei Sun ${ }^{1,2^{*}}$ (D)
}

\begin{abstract}
Background: Hu sheep, a unique Chinese breed with high reproductive performance, are also well known for their rare white lambskin in China. The quality of lambskin is affected by hair follicles, and dermal papilla cells are an important component of hair follicles that plays a key role in hair follicle growth and development. This study helps elucidate the effect of miR-148a and miR-10a on hair follicle growth and development.

Results: Based on the results of gene chip and high-throughput sequencing, bone morphogenetic protein 7 (BMP7) was used as a research object. Bioinformatics analysis and the dual-luciferase reporter system indicated that, along with Western blot and quantitative real-time polymerase chain reaction (qRT-PCR) that miR-148a and miR-10a target relationships with BMP7. BMP7 was the target gene both for miR-148a and miR-10a by the dual-luciferase reporter system and Western blot. Hu sheep dermal papilla cells were successfully isolated and purified, and after transfecting miR-148a/miR-10a mimics and inhibitors into dermal papilla cells, a Cell Counting Kit-8 (CCK-8) was used to determine that miR-148a/miR-10a inhibited the proliferation of Hu sheep dermal papilla cells. In addition, after the overexpression of miR-148a, the expression levels of Smad3 $(P<0.05)$, Smad6 $(P<0.05)$, Smad4 $(P<0.01)$, and Smad5 $(P<0.01)$ were significantly higher than those of the control groups. After the inhibition of miR-148a, the expression levels of Smad3 $(P<0.05)$, Smad4 $(P<0.05)$, and TGF- $\beta(P<0.01)$ were significantly lower than those of the control groups. After the overexpression of miR-10a, the expression levels of Smad1 $(P<0.01)$, Smad2 $(P<0.05)$, Smad4 $(P<0.01)$, Smad5 $(P<0.01)$, and TGF- $\beta(P<0.05)$ were significantly lower than those of the control groups. After the inhibition of miR-10a, the expression levels of Smad1 $(P<0.01)$ and Smad2 $(P<0.05)$ were significantly lower than those of the control groups.
\end{abstract}

Conclusions: These results revealed the target relationship between miR-148a, miR-10a and BMP7, and the effect of miR-148a and miR-10a on the proliferation of dermal papilla cells. They will provide the basis for a follow-up study on how miR-148a, and miR-10a mediate BMP7 regulation of hair follicle growth and development.

Keywords: Hu sheep, miR-148a, miR-10a, BMP7, Dermal papilla cell

\section{Background}

The lambskin of Hu sheep is affected by various factors, and the type of pattern on the skin is one of the most important indicators of $\mathrm{Hu}$ sheep lambskin quality. A small wave pattern indicates higher quality than that of medium and large wave patterns $[1,2]$. The density,

\footnotetext{
* Correspondence: jywang@yzu.edu.cn; dkxmsunwei@163.com ${ }^{1}$ College of Animal Science and Technology, Yangzhou University, Yangzhou 225009, China

Full list of author information is available at the end of the article
}

fineness, and curvature of the wool are the key factors determining the quality of lambskin. These traits may be regulated by different candidate genes in the epidermis, such as BMP7, $\beta$-catenin and Eda/Edar, which affect the structural characteristics of the hair phenotype [3-5]. To explore the manifestation of hair phenotypes, it is necessary to study the growth and development of hair follicles, which are composed of various types of cells $[6,7]$. The dermal papilla cells provide the necessary stimulation signals for the formation of hair follicles and the

(c) The Author(s). 2019 Open Access This article is distributed under the terms of the Creative Commons Attribution 4.0 International License (http://creativecommons.org/licenses/by/4.0/), which permits unrestricted use, distribution, and reproduction in any medium, provided you give appropriate credit to the original author(s) and the source, provide a link to the Creative Commons license, and indicate if changes were made. The Creative Commons Public Domain Dedication waiver (http://creativecommons.org/publicdomain/zero/1.0/) applies to the data made available in this article, unless otherwise stated. 
growth of hair shafts [8], which also control the size and shape of hair through regulating the number of hair cells [9]. The growth and development of hair follicles is dependent on dermal papilla cells to provide important nutrients and signal regulators $[10,11]$. The dermal papilla cell not only regulates hair follicle growth and development, but also is considered as a versatile stem cell [12].

Mammalian hair follicles undergo a unique process of occurrence and differentiation in both embryonic and birth stages. Many signaling pathways are involved, but the signal cascade is not completely clear. Self-renewal and periodic development of hair follicles are regulated by synergistic or antagonistic effects of signaling molecules consisting of related factors and receptors in epidermal and mesenchymal cells [13]. This process also involves a number of signal transduction pathways that regulate the interaction of epidermal and mesenchymal components.

Currently, many of studies have shown that the transforming growth factor (TGF)- $\beta /$ Smads, Wnt, Notch, and Shh signaling pathways are involved in the regulation of hair follicle growth and development [14-18], among which the TGF- $\beta /$ Smads and Wnt signaling pathways have been confirmed to participate in the regulation mechanism of hair follicle differentiation and formation. Most members of the $B M P$ family belonging to the TGF- $\beta$ superfamily are the important signaling molecules involved in hair follicle development [19]. TGF- $\beta$ plays an important role in regulating cell growth and differentiation. Furthermore, it is crucial to hair follicle development and formation. Smads is a unique signal factor in the TGF- $\beta /$ Smads signaling pathway. When the corresponding receptor on the cell membrane surface binds to TGF- $\beta 1$, Smads is responsible for the transmission of the TGF signal from the receptor into the nucleus [20]. Studies have shown that Smads exerts regulatory effects on hair follicle development, periodic growth and pigmentation [21, 22]. BMP7, one of the most biologically active proteins in the BMP family, is also an important signaling molecule involved in hair follicle development.

MicroRNAs (miRNAs) are a class of short (18-24nt) single-stranded non-coding RNAs that can mediate gene silencing at the post-transcriptional level. As shown in recent studies, miRNAs are widely participate in the occurrence and periodic growth of hair follicles. The miRNAs in various types of hair follicle cells constitute an extremely complex network regulation system under the interaction of numerous regulatory factors and signaling pathways so that they can regulate hair follicle morphogenesis and periodic development [23, 24]. Ma et al. [25] screened 10 differentially expressed hair follicle-related miRNAs by transcriptome profiling, and the dual-luciferase reporter system verified that let-7a negatively regulates c-Myc and FGF5. Let-7a was involved in the regulation of hair follicle growth and development.

As illustrated from other study [26], miR-214 directly targets EZH2 to affect the expression of $\beta$-catenin and TCF-4 in the Wnt/ $\beta$-catenin signaling pathway. MiR-214 can be considered as a candidate miRNA in the process of hair follicle development, and miR-399-5p [27], miR195-5p [28] and miR-200 [29] are associated with hair follicle growth and development. Bai et al. [30] revealed that miR-148a-3p was significantly upregulated at the categen and telogen stages. MiR-148a-3p was enriched in many pathways and is involved in hair follicle growth and development. Yang et al. [31] found that miR-148b was highly expressed in the hair follicle growth phase and could promoted the proliferation of hair follicle cells. Moreover, miR-148b could also targeted NFAT5 and upregulated the expression of $\beta$-catenin, $c y c D, c-j u n$ and $W n t 10 b$ to activate the $\mathrm{Wnt} / \beta$-catenin signaling pathway. Although no direct studies have demonstrated that miR-148a is associated with the development of hair follicles, we hypothesized that because miR-148a is a member of the miR-148 family, it might also participate in the regulation of hair follicle growth and development in a manner similar to that of miR-148b. MiR-10a belongs to the miR-10/miR-100 family, and there have been many studies on the control that MiR-10a exerts during disease because of its location adjacent to the tumor-associated Hox gene family [32]. At present, it was found that miR-10a modulates the secretion of inflammatory cytokines and promotes the proliferation of promyelocytic leukemia cells [33, 34]. However, there are few reports on miR-10a and hair follicles. At present, miRNAs have been reported in the research on $\mathrm{Hu}$ sheep hair follicles, but they were only mentioned in the screening of differential miRNAs in hair follicles, indicating a lack of more in-depth research.

In this study, the effects of miR-148a and miR-10a on $\mathrm{Hu}$ sheep dermal papilla cell were explored, and the results will enrich the current research on hair follicle growth and development at the cellular and molecular levels. This research also provides a theoretical basis and new research ideas for improving the quality of $\mathrm{Hu}$ sheep lambskin.

\section{Results \\ Isolation, culture and identification of Hu sheep dermal papilla cells}

The $\mathrm{Hu}$ sheep dermal papilla cells were separated by centrifugation combined with neutral protease and type IV collagenase digestion. They were observed to have a circular or elliptical shape under an inverted fluorescence microscope. On the day after cell isolation and culture, individual cells were observed under a digital microscope (Fig. 1a). Within one week, $85 \%$ of cells 
adhered to the Petri dish, and the cell proliferation rate was significantly accelerated. The cell body was large with a triangular or polygonal shape (Fig. 1b). The dermal papilla cells presented a radial growth trend 6 days later, and the cells gradually lost their original shape and formed a dense region (Fig. 1c). After 12 days, the cells gradually merged into cell clumps, and the cells around the clumps grew radially outward.

The cells in the central region appeared to be multilayered and they accumulated. They showed a tendency of growth with agglutination (Fig. 1d). This characteristic was still retained when the Hu sheep dermal papilla cells reseached the 20th generation. PAS staining revealed that the cytoplasm was different shades of purple, the nuclei were pale blue, and the edges of the dermal papilla cells were dark purple (Fig. 2 I-A). After staining with AB-PAS, the dermal papilla cell cytoplasm was fuchsia and the nuclei were cyan (Fig. 2 I-B). After toluidine blue staining, the dermal papilla cells showed metachromia, including dark blue $(\mathrm{pH}=5)$ (Fig. $2 \mathrm{I}-\mathrm{C})$ and fuchsia $(\mathrm{pH}=6)$ (Fig. $2 \mathrm{I}-\mathrm{D})$. Finally, immunofluorescence staining was used to detect the expression of $\alpha$ smooth muscle actin ( $\alpha$-SMA), a specific marker of dermal papilla cells. Examination with a fluorescence inverted microscope revealed that the nuclei of dermal papilla cells were stained blue, and the cytoplasm was stained green (Fig. 2 II). It was confirmed that the cells in this study were Hu sheep dermal papilla cells.

\section{Dual-luciferase assay between miR-148a, miR-10a and BMP7}

First, we verified the transfection effects of miR-148a and miR-10a mimics and inhibitors. The mimic/ mimic-NC and inhibitor/inhibitor-NC of miR-148a and miR-10a were transfected into $\mathrm{Hu}$ sheep dermal papilla cells to determine their effects in dermal papilla cells. The results showed that the expression levels of miR-148a and miR-10a increased in the cells after miR-148a mimic/mimic-NC, and miR-10a mimic/mimic-NC were transfected into dermal papilla cells, while the expression levels were inhibited after transfection of miR-148a inhibitor/inhibitor-NC and miR-10a inhibitor/inhibitor-NC. Therefore, miRNA mimics and inhibitors could be used in subsequent experiments (Fig. 3).

According to target gene prediction via Findtar3 (http://bio. sz.tsinghua.edu.cn/), RNA22 (http://cbcsrv.watson.ibm.com/ rna22.htmL), miRBase (http://www.mirbase.org/) and miRanda (http://www.microrna.org/microrna/home.do) bioinformatics online software, we predicted the potential target miRNAs of BMP7. Through the intersection of the prediction and the miRNA sequencing results of the different patterns, two possible miRNAs (miR-148a, miR-10a) were selected as candidate miRNAs. The dual-luciferase reporter assay detected the fluorescence activity after transfection of miRNA mimics and inhibitors in Hu sheep dermal papilla cells for 36 $\mathrm{h}$. The results showed that the relative luciferase activity in
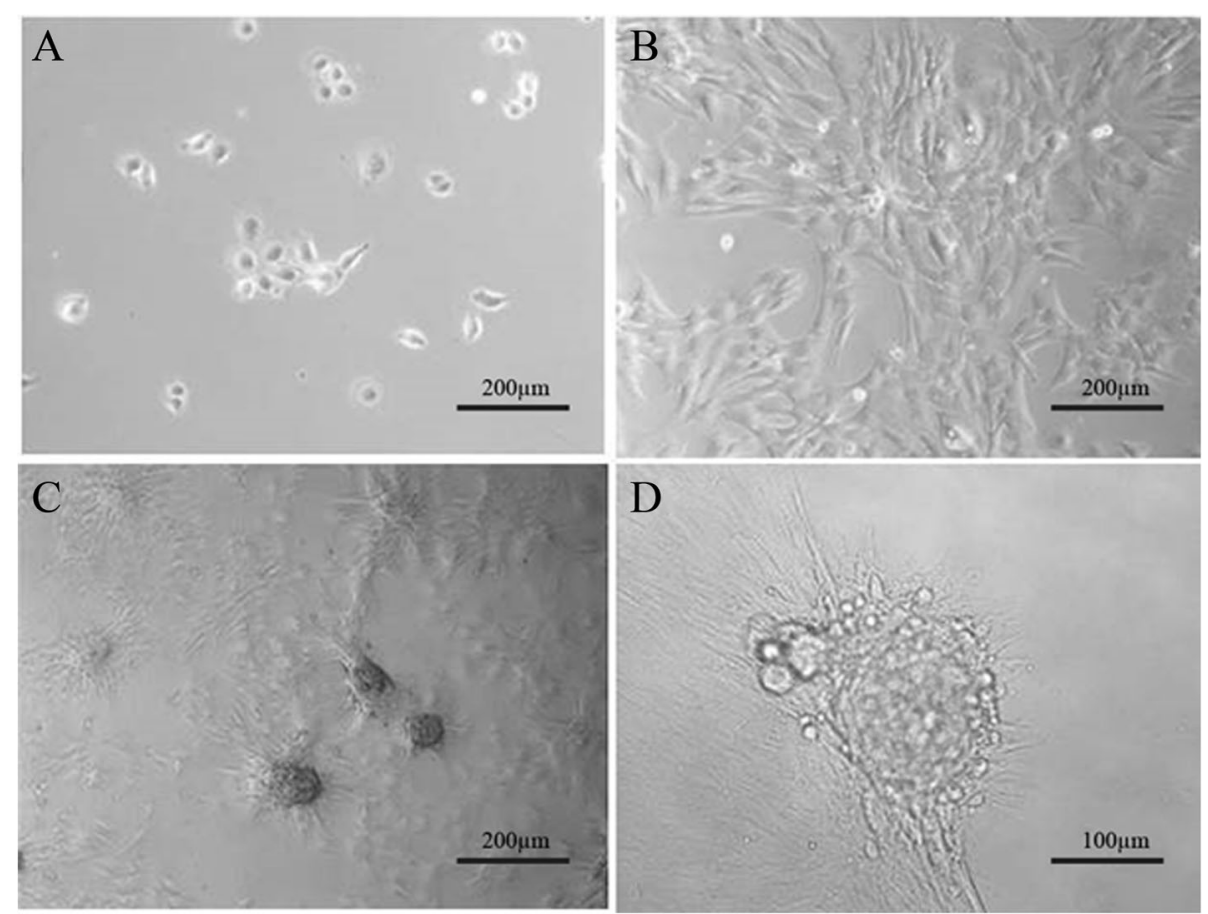

Fig. 1 Sheep dermal papilla cells. a, b, and c show the cell morphology on the 2nd, 6th, and 12th days of cultivation (50x). $\mathbf{d}$ is the cell morphology on the 12th day of cultivation (100x) 

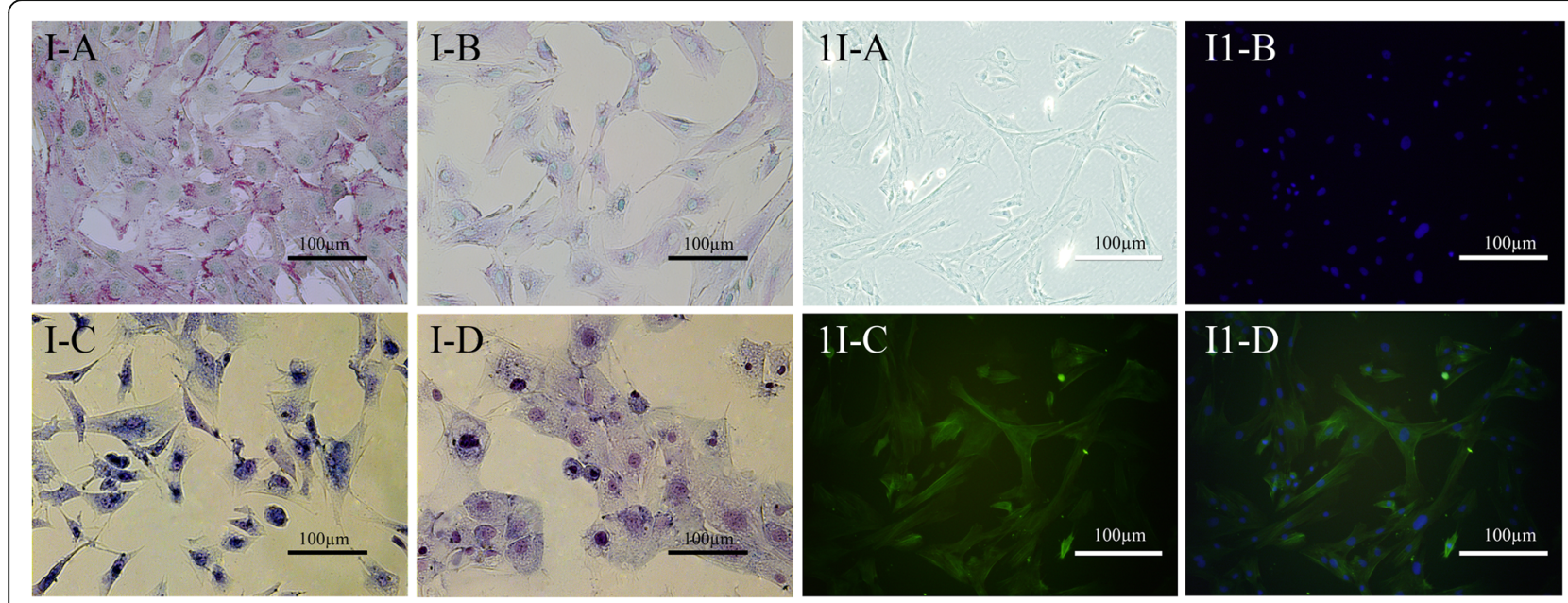

Fig. 2 The identification of dermal papilla cells. I-A: PAS stain (100x), I-B AB-PAS stain (100x), I-C: toluidine blue stain (pH =0.5, 100x), I-D: toluidine blue stain ( $\mathrm{pH}=6.0,100 \times)$; II-A: light microscopy image of dermal papilla cells, II-B: nuclear staining with 4,6-diamidino-2-phenylindole (DAPI), II-C: The immunofluorescence results for dermal papilla cells, II-D: merge image of II-B and II-C

the WT group (miR-148a mimic + WT) was significantly lower than that in the control group (miR-148a mimic-NC+ WT) $(P<0.01)$. The luciferase activity was not significantly different between the MUT1 group (miR-148a mimic+MUT1) and the control group (miR-148a mimic-NC+ MUT1) $(P>0.05)$ (Fig. 4b). The luciferase activity in the WT group (miR-10a mimic + WT) was significantly lower than that in the control group (miR-10a mimic-NC+WT) $(P<$ 0.05 ), while the luciferase activity in the MUT2 group (miR10a mimic + MUT2) was not significantly different as compared to the control group (miR-10a mimic-NC+ MUT2) $(P>0.05)$ (Fig. 4c). These results showed that there was binding between the seed regions of miR-148a and miR$10 \mathrm{a}$ and the 3'UTR region of BMP7.

\section{MiR-148a and miR-10a affected BMP7 expression at the mRNA and BMP7 protein levels}

To further validate the target relationship between $B M P 7$ and $\mathrm{miR}-148 \mathrm{a} / \mathrm{miR}-10 \mathrm{a}$, we examined the expression of $B M P 7$ mRNA and protein after overexpression
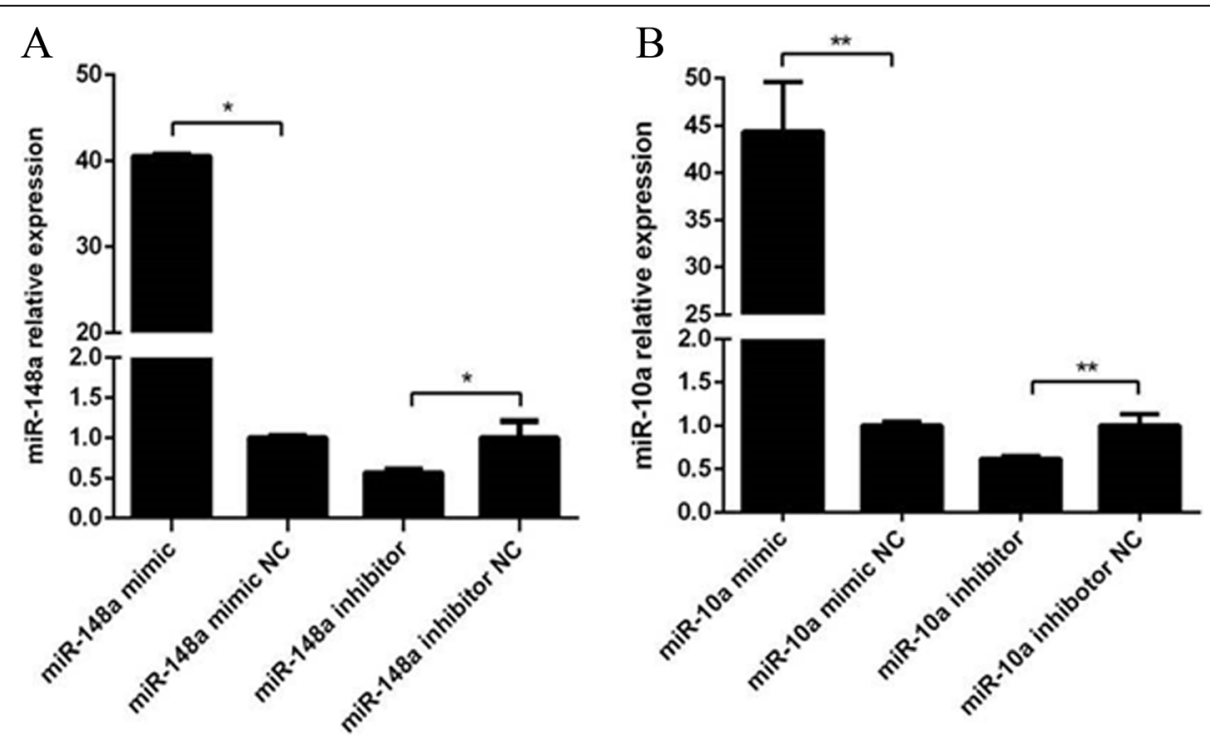

Fig. 3 The relative expression of miR-148a and miR-10a $(n=3)$. a The relative expression of miR-148a in Hu sheep dermal papilla cells after overexpression or inhibition by miR-148a mimic or miR-148a inhibitor, $\mathbf{b}$ The relative expression of miR-10a after overexpression or inhibition by miR-10a mimic or miR-10a inhibitor. * represents a significant difference between the experimental group and the control group $(P<0.05)$. ${ }^{*}$ represents a great significant difference between the experimental group and the control group $(P<0.01)$ 


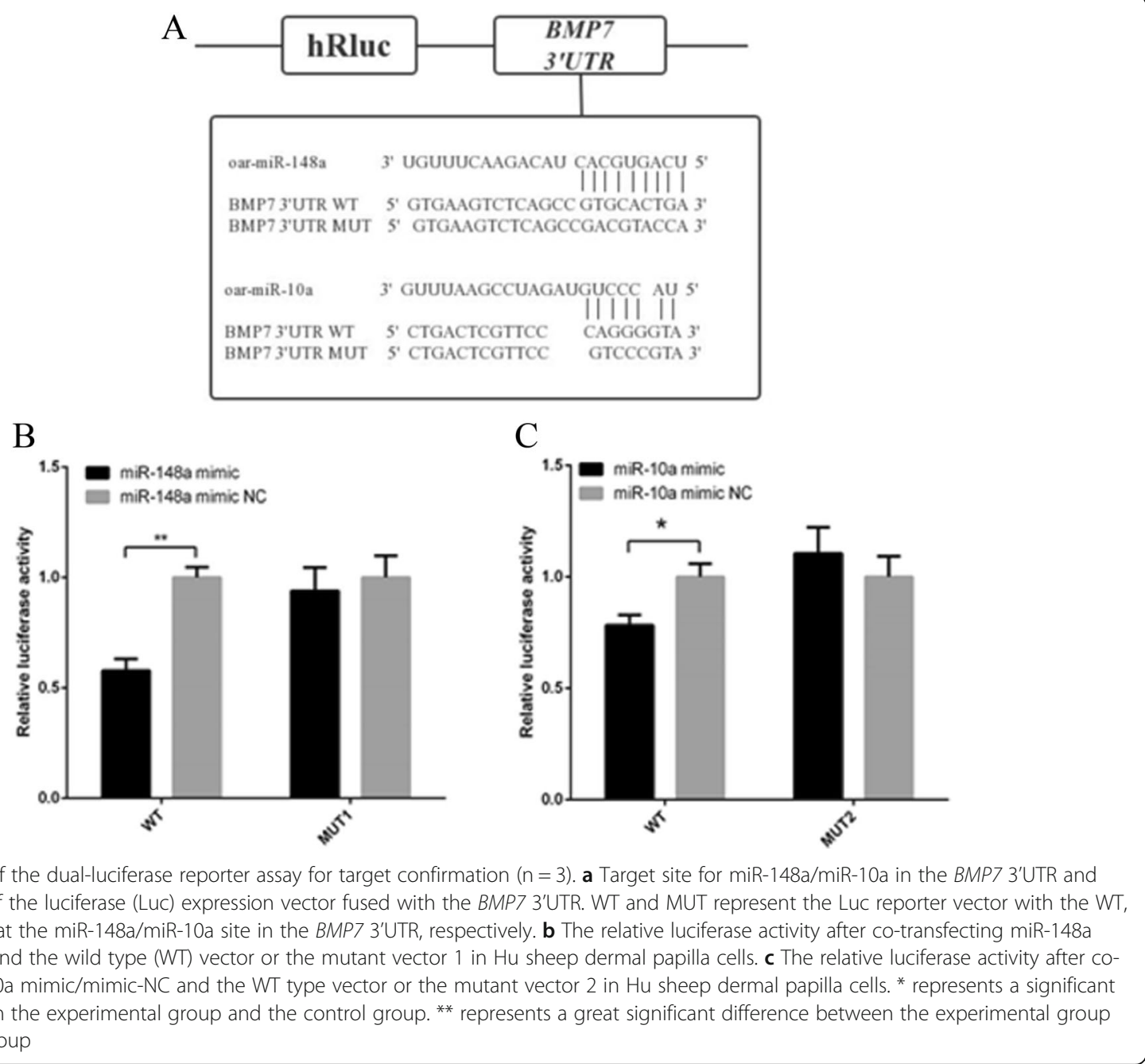

and inhibition of miR-148a and miR-10a in dermal papilla cells. The results showed that the expression of $B M P 7$ was far lower than that of the control group after overexpression of miR-148a $(P<0.01)$, and it was far higher than that of the control group after inhibiting miR-148a $(P<0.01)$. The expression of BMP7 was significantly lower than that of the control group after overexpression of miR-10a $(P<0.05)$, and it was higher than that of the control group after inhibiting miR-10a $(P>0.05)$. Although the difference was not significant, the expression of miR-10a in the inhibition group was still increased (Fig. 5a).

After overexpression of miR-148a and miR-10a in dermal papilla cells, the expression of BMP7 protein was lower than that of the negative control group. However, after inhibiting miR-148a and miR-10a, the expression of BMP7 protein was higher than that of the negative control group (Fig. 5b). The results showed that both miR-148a and miR-10a inhibited the expression of BMP7 protein, which further confirmed that $B M P 7$ is a target gene of miR-148a and miR-10a.
Effects of miR-148a and miR-10a on proliferation of $\mathrm{Hu}$ sheep dermal papilla cells

The growth rate of dermal papilla cells was detected using CCK-8 (No.CK04, Dojindo, Kumamoto, Japan) after transfection of miR-148a/miR-10a mimics and inhibitors. Compared with the negative control group, the proliferation rate of dermal papilla cells transfected with miR-148a mimic and miR-10a mimic for 24,48 , and 72 $\mathrm{h}$ was significantly decreased $(P<0.05)$, while the proliferation of dermal papilla cells transfected with miR-148a inhibitor and miR-10a inhibitor for 24,48 , and $72 \mathrm{~h}$ was significantly higher than that of the negative control group $(P<0.05)$ (Fig. 6). It was observed that both miR148a and miR-10a inhibited the proliferation of $\mathrm{Hu}$ sheep dermal papilla cells.

\section{Effects of miR-148a and miR-10a on major genes in the TGF- $\beta /$ Smads pathway}

The TGF- $\beta$ /Smads pathway plays an important role in regulating the growth and development of hair follicles, 


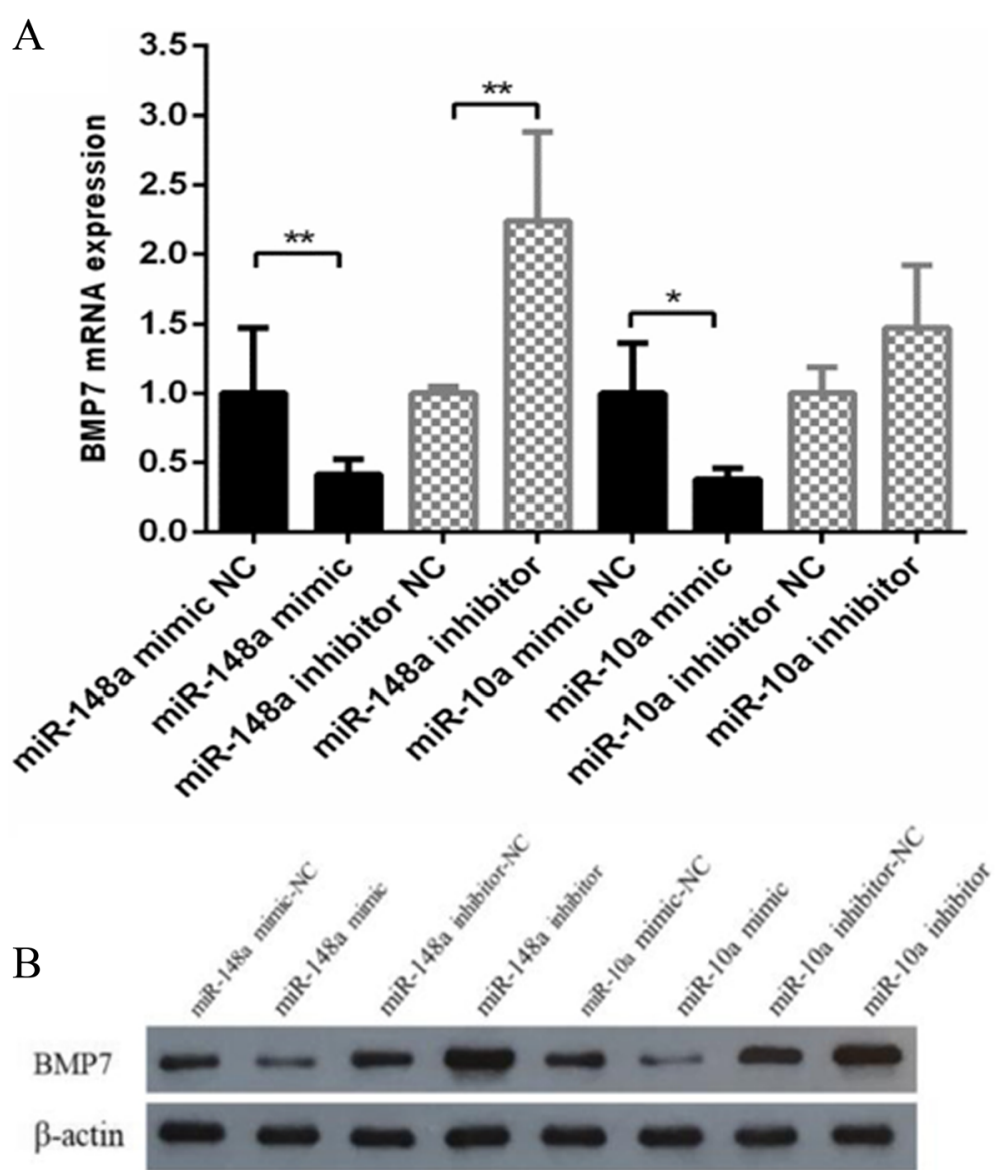

Fig. 5 The expression levels of BMP7 after overexpression and inhibition of miR-148a/miR-10a in dermal papilla cells $(n=3)$. a The mRNA expression of BMP7. $\mathbf{b}$ The protein expression of BMP7. * represents a significant difference between the experimental group and the control group. ${ }^{* *}$ represents a great significant difference between the experimental group and the control group

and $B M P 7$ is involved in the TGF $\beta /$ Smads signaling pathway. To further explore the effects of miR-148a and miR$10 \mathrm{a}$ on the TGF $\beta /$ Smads signaling pathway, the key genes Smad1, Smad2, Smad3, Smad4, Smad5, Smad6, and $T G F-\beta 1$ in the TGF $\beta /$ Smads signaling pathway were detected by qRT-PCR after overexpression and inhibition of $\mathrm{miR}-148 \mathrm{a}$ and miR-10a. After overexpression of miR148a, the expression of Smads genes was higher than that of the control group, among which, the Smad3 and Smad6 expression levels were significantly increased $(P<$ 0.05), and those of Smad4 and Smad5 were significantly increased $(P<0.01)$. However, the expression level of TGF- $\beta 1$ was lower than that of the control group (Fig. 7a). After inhibiting miR-148a, the expression of Smads genes and TGF- $\beta 1$ was lower than that of the control group, and $S m a d 3$ and Smad4 expression levels were significantly decreased $(P<0.05)$, while there was an extremely significant difference between the expression of TGF- $\beta 1$ and the control group $(P<0.01)$ (Fig. 7b).

After overexpression of miR-10a, the expression of Smads genes in the experimental group was lower than that in the control group, and the expression of Smad2 was significantly lower than that in the control group $(P<0.05)$. The expression of Smad1, Smad4 and Smad5 was far lower $(P<0.01)$, while the expression of TGF- $\beta 1$ was significantly higher than that of the control group $(P<0.05)$ (Fig. 7c). After inhibiting miR-10a, the expression of Smads and TGF- $\beta 1$ was lower than that in the control group Smad1 was significantly lower $(P<0.05)$, and Smad1 was even lower $(P<0.01)$ (Fig. $7 \mathrm{~d})$.

\section{Discussion}

Currently, bioinformatics analysis is the most common method used to find target genes of miRNAs. We can calculate and filter the target gene or miRNAs targeting a specific gene by the interaction between the target gene and the miRNAs [35]. Common predictive software includes TargetScan, MiRBase, RNA22, PicTar, and Findtar3. Among them, RNA22 and Findtar3 are commonly used to predict miRNA and some specific species target points. In order to explore the BMP7 target miRNAs of the sheep, RNA22 and Findtar3 were selected. 

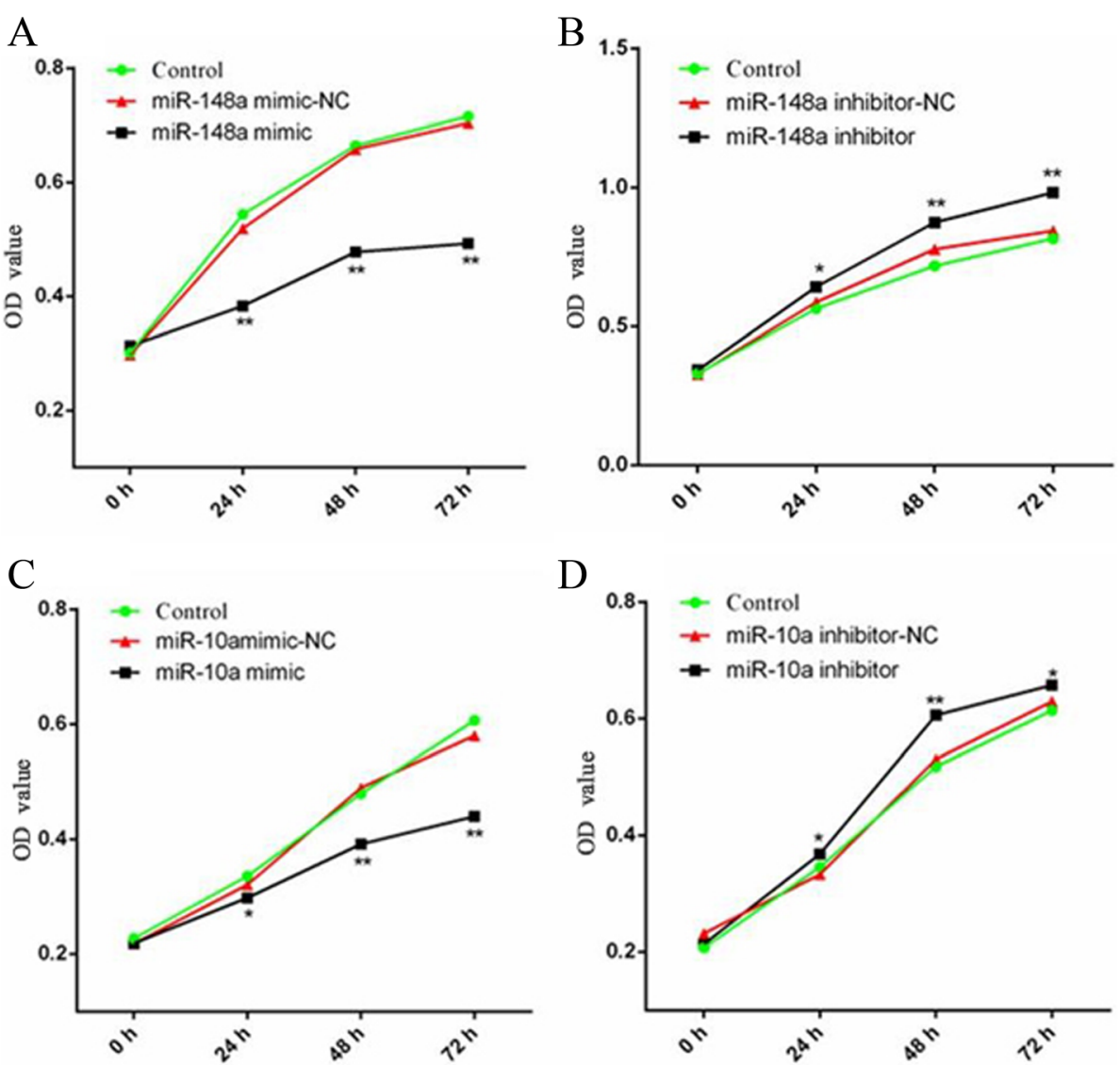

Fig. 6 The results of Hu sheep dermal papilla cell proliferation with the CCK-8 detection assay $(n=3)$. a The proliferation of Hu sheep dermal papilla cells after the overexpression of miR-148a. $\mathbf{b}$ The proliferation of Hu sheep dermal papilla cells after the inhibition of miR-148a, $\mathbf{c}$ The proliferation of Hu sheep dermal papilla cells after the overexpression of miR-10a, $\mathbf{d}$ The proliferation of Hu sheep dermal papilla cells after the inhibition of miR-10a. * represents a significant difference between the experimental group and the control group $(P<0.05)$. ${ }^{*}$ represents a great significant difference between the experimental group and the control group $(P<0.01)$

Based on the results of high-throughput sequencing, miR-148a and miR-10a were selected for subsequent experimental studies.

Through complementation or incomplete complementation with the target mRNA, mature miRNAs direct the RNA-induced silencing complexes to degrade the target mRNA or inhibit translation of the target mRNA [36]. In order to further confirm that miR-148a/miR-10a targets $B M P 7$, Western blot and qRT-PCR were used to detected BMP7 mRNA and protein expression levels through overexpression and inhibition of miR-148a and miR-10a. It was found that both miR-148a and miR-10a directly bind to the targeted binding site in $B M P 7$ 3'UTR and promote the degradation of BMP7 mRNA to reduce the BMP7 protein level. It has been confirmed that $B M P 7$ is a target gene of miR-148a and miR-10a, but the influence of miR-148a and miR-10a on Hu sheep dermal papilla cells requires further exploration.

The development of hair follicles is regulated by numerous signal factors. The interaction between different factors and different signal pathways constitutes an extremely complex regulatory network during the process of hair follicle growth. As an important regulator in the animal body, miRNA is also involved in the development and formation of hair follicles. There have been many reports on the function of miR-148a and miR-10a in cancer and oncogenesis, but few studies have been reported on hair follicles. Through overexpression and inhibition of miR-148a and miR-10a in dermal papilla cells, it was found that miR-148a and miR-10a inhibited the proliferation of dermal papilla cells. However, miR-148b can promote the proliferation of human dermal papilla cells and human hairy maternal cells. After analyzing the results of this study, it was determined that miR-148a and miR-148b were members of the same family, but they had different effects on the proliferation of dermal papilla cells. This might be caused by a variety of factors, such as structural differences between miR-148a and miR-148b or the different growth periods of the hair follicles during the detection. MiRNAs even have different effects on hair follicles in different species. 


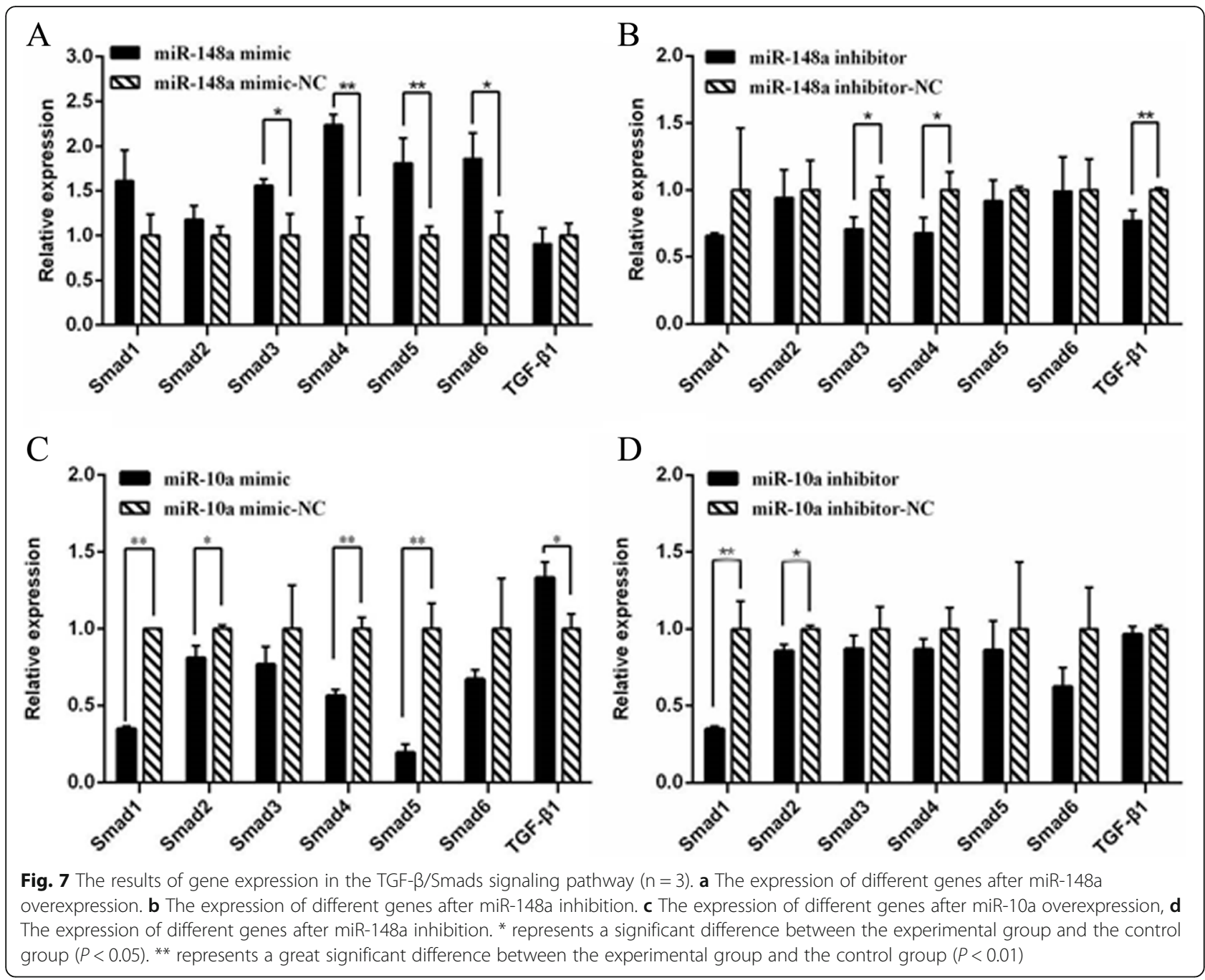

Previous studies have shown that some members of the $B M P$ family play an important role in the regulation of hair follicle development, and the expression levels are different at different stages [37]. In this family, $B M P 2$ and $B M P 4$ are believed to have the effect of inhibiting the development of hair follicles [38-41]. Interestingly, by overexpressing and inhibiting miR-148a and miR-10a, we found that both miR148a and miR-10a inhibited the proliferation of $\mathrm{Hu}$ sheep dermal papilla cells. Combining these data with the results of the dual-luciferase reporter assay, we speculated that BMP7 may promote the proliferation of papilla cells, but the specific mechanism requires further study. In addition, there were reports that $B M P 7$ was highly expressed when the hair follicle was in the growth phase, especially when the hair follicle cells started to proliferate at the basement membrane. When the hair follicle entered the degenerative phase or the resting phase, $B M P 7$ was low or even not expressed [42]. This indicates that BMP7 may promote the proliferation of hair follicle cells in the hair follicle growth phase. However, Wang [43] reported that BMP7 has an inhibitory effect on the growth of wool length in fine wool sheep. This is not inconsistent with the speculation of the current study, because this study collected 2-day-old $\mathrm{Hu}$ lamb hair follicles, and Wang used follicles from adult Aohan fine wool sheep. One potential explanation is that different sheep breeds, different cycles, and other factors will have different effects on the results. Some studies have revealed that miR-148 and miR-10 inhibited the proliferation of different types of cells. For example, miR-148-3p inhibited the growth of glioblastoma by targeting DNMT1 and PCa cell growth in vivo $[44,45]$. It was also found that miR-148a could suppress human renal cell carcinoma malignancy by targeting AKT2 [46]. Additionally, miR-10a was found to inhibit cell proliferation by targeting BCL6 in diffuse large B-cell lymphoma [47]. MiR-10a-5p was proved to have the capacity to inhibit keratinocyte proliferation [48]. According to these reports, miR-148a and miR-10a can inhibit cell proliferation which is consistent with our results.

Studies have shown that BMP7 and TGF- $\beta 1$ are mutually antagonistic. When miR-148a is overexpressed in 
Hu sheep dermal papilla cells, the expression level of $B M P 7$ will decrease relative to miR-148a targeting to $B M P 7$. If there is no other condition, the expression of TGF- $\beta 1$ will be theoretically upregulated. However, $T G F-\beta 1$ expression was downregulated after overexpression of miR-148a. In the TGF- $\beta /$ Smads pathway, Smad6 and $S m a d 7$ are the major negative regulators of the TGF- $\beta /$ Smads signal transduction pathway. Smad6 inhibits the phosphorylation of $S m a d 2$ and $S m a d 3$ by binding to type I receptors activated by TGF- $\beta 1$, thereby negatively regulating the signal transduction of TGF- $\beta 1$ [49]. We hypothesized that Smad6 exerts a major influence in the overexpression and inhibition of miR-148a in Hu sheep dermal papilla cells, which involves inhibiting the phosphorylation of $\operatorname{Smad} 2$ and Smad3, thereby impeding the signal transduction of TGF- $\beta 1$. When overexpression or inhibition of miR-10a occurs, the expression of Smad1 to Smad6 is downregulated, although the opposite trend occurs for TGF- $\beta 1$ expression. We speculate that miR-10a could be associated with the TGF- $\beta$ /Smads pathway, but it might also be related to other pathways.

\section{Conclusions}

In summary, the results of this study to some extent reveal that miR-148a and miR-10a can inhibit the proliferation of $\mathrm{Hu}$ sheep dermal papilla cells, and they are associated with hair follicle growth and development. However, the growth and development of hair follicles is a delicate and extremely complex process. Therefore, follow-up studies are required to further reveal the mechanisms of hair follicle growth and development.

\section{Methods}

\section{Isolation, culture and identification of Hu sheep dermal} papilla cells

A lively and healthy 2-day-old $\mathrm{Hu}$ lamb was selected from a Suzhou stud farm in China, approximately $1 \mathrm{~cm}^{2}$ of the dorsal skin tissue was surgically removed, and the wound was then swabbed with iodine and bandaged with medical gauze. After disinfection for $15 \mathrm{~s}$ with $75 \%$ alcohol, the skin was washed with phosphate-buffered saline (PBS) containing a double antibody, and finally placed in Dulbecco's modified Eagle's medium (DMEM) containing penicillin and streptomycin to separate and culture the dermal papilla cells. Using a sterile surgical blade to remove some obvious fat and connective tissue on the surface, the tissue was cut into a $1-\mathrm{mm}^{2}$ block, and the dermal papilla cells were cultured by neutral protease and collagenase digestion. According to the characteristics that different cells have different sensitivities to the enzymes, the dermal papilla cells were subcultured and purified by differential centrifugation. Finally, the dermal papilla cells were identified by periodic acid Schiff
Table 1 Amplification primers information of BMP7 $3^{\prime} U T R$ sequence

\begin{tabular}{lll}
\hline Name & Primer & $\begin{array}{l}\text { Length/ } \\
\text { bp }\end{array}$ \\
\hline BMP7- & GCGGCTCGAGCTCTTCCTGGAAGTCACACGCTT & 480 \\
F(Xhol) & & \\
BMP7-R(Notl) & AATGCGGCCGCTITIITITITCATCAT & \\
& CGTTITA & \\
\hline
\end{tabular}

Note: The underline is the enzyme cleavage site, and the sequence before underline is the protection base

(PAS), Alcian blue-periodic acid Schiff (AB-PAS), toluidine blue staining and immunofluorescence staining and nuclear staining with 4',6-diamidino-2-phenylindole (DAPI).

\section{Dual-luciferase assay between miR-148a, miR-10a and BMP7}

The 3' untranslating region (3'UTR) sequence of the $B M P 7$ was amplified, and cloned into the pmiR-RBREPORTTM dual-luciferase reporter vector using the Trelief SoSoo Cloning Kit (No. TSV-S1; TsingKe, Beijing, China) (Table 1). To construct two mutant vectors, oar-BMP7-MUT1 (TGCACTG was mutated to ACGTACC at 318-324 bp) and oar-BMP7-MUT2 (CAGGG was mutated to GTCCC at 334-338 bp) (Table 2), a Fast Site-Directed Mutagenesis Kit (No. KM101; Tiangen, Beijing, China) was used. Human embryonic kidney HEK293T cells were cultured in DMEM/ Ham's F12 nutrient mixture (F12) (Gibco, NY, US) supplemented with $10 \%$ fetal bovine serum (Sigma, Santa Clara, CA, US) with $5 \% \mathrm{CO}_{2}$ in air at $37^{\circ} \mathrm{C}$. The HEK293T cells were cultured in 24-well plates to $80 \%$ confluence and transfected using FuGENE ${ }^{\circ}$ HD transfection reagent (Promega, Madison, WI, US), according to the manufacturer's instructions. MiRNA mimic/inhibitor was purchased from Guangzhou RiboBio Co.,Ltd. The experimental groupings were: miR148a mimic + WT, miR-148a mimic-NC + WT, miR148a mimic + MUT1, miR-148a mimic-NC + MUT1 and miR-10a mimic + WT, miR-10a mimic-NC + WT, miR10a mimic + MUT2, miR-10a mimic-NC + MUT2. Three parallel experimental groups were set up for each sample. Dual-luciferase reporter assays were performed according to the Promega Dual-Glo Luciferase-Assay System reagent instructions.

Table 2 Mutation vector construction of BMP7 3'UTR

\begin{tabular}{ll}
\hline Name & Primer sequence \\
\hline Oar-BMP7-MUT1-F & TCAGCCGACGTACCACTCGTTCCCAGGGTAA \\
Oar-BMP7-MUT1-R & GAACGAGTGGTACGTCGGCTGAGACTTCACAGC \\
Oar-BMP7-MUT2-F & CTCGTTCCGTCCCGTAATACGACACTCTTCA \\
Oar-BMP7-MUT2-R & GTAATTACGGGACGGAACGAGTCAGTGCACG \\
\hline
\end{tabular}

Note: The underline means mutation sequence 
Table 3 Primers information

\begin{tabular}{|c|c|c|c|}
\hline Genes & References sequences & Sequences $\left(5^{\prime} \rightarrow 3^{\prime}\right)$ & Product length (bp) \\
\hline Smad1 & AY035385 & $\begin{array}{l}\text { F: GAAAGCCCCGTTCTTCCTCC } \\
\text { R: GTTGGGCTGCTGGAAAGAAT }\end{array}$ & 150 \\
\hline Smad2 & AY185300.1 & $\begin{array}{l}\text { F: GCAGGAATTGAGCCACAGAG } \\
\text { R: GCTGCAAATCCAAGCTCTGA }\end{array}$ & 172 \\
\hline Smad3 & AF508024.1 & $\begin{array}{l}\text { F: GGACGACTACAGCCATTCCA } \\
\text { R: ATTCGGGGAGAGGTTTGGAG }\end{array}$ & 172 \\
\hline Smad4 & NM_001267886 & $\begin{array}{l}\text { F:CTTCAGGTGGCTGGTCGG } \\
\text { R:TCCAGGTGATACAACTCGTTCA }\end{array}$ & 177 \\
\hline Smad5 & AF508027 & $\begin{array}{l}\text { F:CCAGTATATCCAGCAGAGATGTT } \\
\text { R:AAGCTTCCCCAACACGATTG }\end{array}$ & 102 \\
\hline Smad6 & XM_004010255.3 & $\begin{array}{l}\text { F: CTGCTCGGACGCCTCTTC } \\
\text { R: GGGTGGCGGTGATTCTGG }\end{array}$ & 105 \\
\hline TGF- $\beta 1$ & NM_001009400 & $\begin{array}{l}\text { F:GGTGGAATACGGCAACAAAATC } \\
\text { R:TGCTGCTCCACTIITAACTTGA }\end{array}$ & 162 \\
\hline GAPDH & NM_001190390.1 & $\begin{array}{l}\text { F: GTCGGAGTGAACGGATTTGG } \\
\text { R: CATTGATGACGAGCTTCCCG }\end{array}$ & 196 \\
\hline
\end{tabular}

\section{qRT-PCR and Western blot}

In order to further explore the influence of mir-148a and mir-10a on related genes in the TGF-beta /Smads signaling pathway, Smad1, Smad2, Smad3, Smad4, Smad5, Smad6, and TGF- $\beta 1$ were selected for qRTPCR and western blot. According to the sheep gene sequence published in GenBank, Primer3web (http:// primer3.ut.ee/) was used to design primers for Smad1, Smad2, Smad3, Smad4, Smad5, Smad6, and TGF- $\beta 1$ (Table 3). After the cells were transfected for $36 \mathrm{~h}$, the total RNA was extracted using RNAsimple Total RNA Kit (Tiangen) and reverse-transcribed into cDNA using a FastQuant RT Kit (with gDNase) (Tiangen). The expression of BMP7 mRNA in the different treatment groups was detected by qRT-PCR using TB Green Premix Ex Taq II (Tli RNaseH Plus) (TaKaRa, Dalian, China), according to the manufacturer's instructions.

For the Western blot analysis, dermal papilla cells were lysed using radioimmunoprecipitation assay lysis buffer (Storng) (CWBIO, Beijing, China). The protein concentrations of different groups were measured with a bicinchoninic acid Protein Assay Kit (Beyotime, Jishou, China). The proteins were separated by SDS-PAGE, transferred to polyvinylidene difluoride membranes, and probed with 1:500 rabbit anti-BMP7 (Sigma, sab2107883, USA) and $1: 1000$ rabbit anti- $\beta$-actin (CWBIO) antibodies, and then with 1: 1000 polyclonal goat anti-rabbit IgG HRG conjugated antibodies (CWBIO). All steps were carried out in accordance with the instructions. Signals were detected with the enhanced chemiluminescence eECL Western Blot kit (CWBIO). Protein was detected and analyzed by the Wes automated Western Blot Analysis System (Protein Simple, CA, US).
Overexpression and inhibition of miR-148a, miR-10a

The culture and transfection methods for $\mathrm{Hu}$ sheep dermal papilla cells were the same as those for HEK293T cells. The dermal papilla cells were transferred to 96 -well plates with $0.25 \%$ trypsin $36 \mathrm{~h}$ after transfection with $\mathrm{miR}-148 \mathrm{a} / \mathrm{miR}-10 \mathrm{a}$ mimics and inhibitors. The medium was discarded after $0,24,48$ and $72 \mathrm{~h}, 10 \mu \mathrm{L}$ CCK-8 solution was added to each well. The OD value was measured at $450 \mathrm{~nm}$ with a Tecan Infinite F200/ M200 microplate reader (Tecan, Shanghai, China) after $2 \mathrm{~h}$. At the same time, the expression of $S m a d 1, S m a d 2$, Smad3, Smad4, Smad5, Smad6, and TGF- 11 was detected using qRT-PCR 24 h hours after transfection.

\section{Data analysis}

The relative gene expression levels were analyzed by the $2^{-\Delta \Delta C T}$ method. Independent sample $t$ tests were performed using SPSS 16.0 software (* denotes $p<0.05$, significant difference; $*$ denotes $p<0.01$, extremely significant difference) [50], and drawing was performed using GraphPad Prism 6 software. Three biological replicates were used for each analysis, and all error bars in the results represent the mean $\pm \mathrm{SD}$.

\section{Abbreviations}

AB-PAS: Alcian Blue-Periodic Acid Schiff; BMP7: Bone morphogenetic protein 7; CCK-8: Cell Counting Kit 8; DAPI: 4', 6-Diamidino-2-Phenylindole; MiRNA: MicroRNA; PAS: Periodic Acid Schiff; qRT-PCR: Quantitative real-time polymerase chain reaction; TGF- $\beta 1$ : Transforming growth factor- $\beta 1$;

UTR: Untranslating Region

\section{Acknowledgments}

We are sincerely grateful to Prof Dr. Wei Sun and Prof Dr. Jinyu Wang in our research team for their valuable guidance in the course of this research work. To all the members of the research team, we do appreciate the moral support and the immense support we received during the period of this research work. We thank Suzhou stud farm in China for allowing sample collection. Finally, we thank LetPub (www.letpub.com) for its linguistic assistance during the preparation of this manuscript. 


\section{Authors' contributions}

WS and JYW designed the experiments. XYL and WG performed and completed the experiments. LHW, CWH, CYJ and YW contributed reagents/materials/analysis tools. XYL wrote the paper. SXZ, SXS and ZFL helped with sample collection. All authors contributed helpful suggestions for this manuscript. All authors read and approved the final manuscript.

\section{Funding}

This work was performed by National Natural Science Foundation of China (31872333), The Projects of Domesticated Animals Platform of the Ministry of Science, Key Research and Development Plan (modern agriculture) in Jiangsu Province (BE2018354), Major new varieties of agricultural projects in Jiangsu Province (PZCZ201739), Jiangsu Agricultural Science and Technology Innovation Fund (CX (18)2003), The Project Funded by the Priority Academic Program Development of Jiangsu Higher Education Institutions, Major projects of Natural Science Research of colleges and universities in Jiangsu Province (17KJA230001), The Project of six peak of talents of Jiangsu Province of China and Postgraduate Innovation Project of Yangzhou University (XKYCX17_060, SJCX18_0804). The funders had no role in the design of the study and collection, analysis, and interpretation of data and in writing the manuscript.

\section{Availability of data and materials}

The data sets supporting the results of this article are included within the article.

\section{Ethics approval and consent to participate}

Verbal consent to participate and allow Hu sheep to be used in this study was obtained from the Suzhou stud farm due to skilled surgical methods and minimal damage to sheep. The animal experiment was also reviewed and approved by the Chinese Ministry of Agriculture (license number: 39) and the Jiangsu Provincial Government Animal Care and Use Committee (IACUC) (license number: 45). All experimental procedures were carried out in strict accordance with the Guidelines for the Care and Use of Laboratory Animals in Jiangsu Province and the recommendations of the Animal Protection and Use Committee of the Ministry of Agriculture of China.

\section{Consent for publication}

Not applicable.

\section{Competing interests}

The authors declare that they have no competing interests.

\section{Author details}

'College of Animal Science and Technology, Yangzhou University, Yangzhou 225009, China. ${ }^{2}$ Joint international research laboratory of agriculture and agri - product safety of Ministry of Education of China, Yangzhou University, Yangzhou 225009, China.

\section{Received: 15 March 2019 Accepted: 8 August 2019}

Published online: 27 August 2019

\section{References}

1. Cheng $\mathrm{RH}$. Identification and classification of Hu sheep lambskin. J Econ Anim. 1980;1:40-1 (In Chinese).

2. Li ZN, Zhang ZL, Du JZ, Han A, Chang YL, Li TX, Zhang QF, Zhang RS. Morphological observation on the formation of Hu sheep lambskin pattern. Sci Agric Sin. 1982;15(3):73-82 (In Chinese).

3. Ni R, Sun W, Yin JF, Lv XY, Wang QZ, Su R, Chen L, Wu WZ, Xu HS, Li Y, Chen JZ, Liu WZ. Histological study on the different hairs of the sheep skin in Hu sheep. Chinese J Anim Sci. 2013;8(9):23-4 (In Chinese).

4. Oshimori N, Fuchs E. Paracrine tgf- $\beta$ signaling counterbalances bmpmediated repression in hair follicle stem cell activation. Cell Stem Cell. 2012; 10(1):63-75

5. Schlake T. Segmental lgfbp5 expression is specifically associated with the bent structure of zigzag hairs. Mech Dev. 2005;122(9):988-97.

6. Millar SE. Molecular mechanisms regulating hair follicle development. J Investig Dermatol. 2002;118(2):216-25.

7. Paus R, Müller-Röver S, Veen CVD, Maurer M, Handjiski B. A comprehensive guide for the recognition and classification of distinct stages of hair follicle morphogenesis. J Investig Dermatol. 1999;113(4):523-32.
8. Oliver RF. Whisker growth after removal of the dermal papilla and lengths of follicle in the hooded rat. J Embryol Exp Morphol. 1966;15(3):331-47.

9. Paus R, Cotsarelis G. The biology of hair follicles. N Engl J Med. 1999;341(7):491-7.

10. Alonso L, Fuchs E. The hair cycle. J Cell Sci. 2006;119(119):391-3.

11. Jahoda CAB, Oliver RF, Reynolds AJ, Forrester JC, Gillespie JW, CserhalmiFriedman PB, Christiana AM, Home KA. Trans-species hair growth induction by human hair follicle dermal papillae. Exp Dermatol. 2001;10(4):229-37.

12. Driskell RR, Clavel C, Rendl M, Watt FM. Hair follicle dermal papilla cells at a glance. J Cell Sci. 2011;124(8):1179-82.

13. Liu ZH, Li N, Ren LM, Hu XX, Zhang WG, Yin J, Li JQ. Advance in the morphogenesis and molecular regulation of hair follicles in cashmere goats. Chinese journal of animal science. Chinese J Anim Sci. 2009;45(5):56-60 (In Chinese).

14. Telerman SB, Rognoni E, Sequeira I, Pisco AO, Lichtenberger BM, Culley O, Viswanathan P, Driskell RR, Watt FM. Dermal blimp1 acts downstream of epidermal $\operatorname{tgf} \beta$ and $w n t / \beta$-catenin to regulate hair follicle formation and growth. J Investig Dermatol. 2017;137(11):2270-81.

15. Plikus MV, Chuong CM. Macroenvironmental regulation of hair cycling and collective regenerative behavior. Cold Spring Harbor Perspect Med. 2014; 4(1):a015198.

16. Demehri $\mathrm{S}$, Kopan R. Notch signaling in bulge stem cells is not required for selection of hair follicle fate. Development. 2009;136(6):891.

17. Lee S, Jin JX, Taweechaipaisankul A, Kim GA, Ahn C, Lee BC. Sonic hedgehog signaling mediates resveratrol to improve maturation of pig oocytes in vitro and subsequent preimplantation embryo development. J Cell Physiol. 2018;233(6):5023-33.

18. Zhang Y, Wu K, Wang L, Wang Z, Han W, Chen D, Wei Y, Su R, Wang R, Liu Z, Zhao Y, Wang Z, Zhan L, Zhang Y, Li J. Comparative study on seasonal hair follicle cycling by analysis of the transcriptomes from cashmere and milk goats. Genomics. 2019;7543(18):30576-7.

19. Botchkarev VA, Sharov AA. Bmp signaling in the control of skin development and hair follicle growth. Differentiation. 2004;72(10):512-26.

20. Massagué J. How cells read tgf-beta signals. Nat Rev Mol Cell Biol. 2000;1(3): 169-78.

21. Kandyba E, Hazen VM, Kobielak A, Butler SJ, Kobiela K. Smad1 and 5 but not smad8 establish stem cell quiescence which is critical to transform the premature hair follicle during morphogenesis towards the postnatal state. Stem Cells. 2014:2:534-47.

22. He W, Li AG, Wang D, Han S, Zheng B, Goumans MJ, Ten Dijke P, Wang XJ. Overexpression of smad7 results in severe pathological alterations in multiple epithelial tissues. EMBO J. 2014;21(11):2580-90.

23. Botchkareva N. MicroRNA/mRNA regulatory networks in the control of skin development and regeneration. Cell Cycle. 2012;11(3):468-74.

24. Cai T, Liu ZH, Wang ZX, Zhao M, Ju HL, Li JQ. miRNA in regulation of skin and hair follicle development. Hereditas. 2013;35(9):1087-94.

25. Ma T, Li J, Jiang Q, Wu S, Jiang H, Zhang Q. Differential expression of miRlet7a in hair follicle cycle of Liaoning cashmere goats and identification of its targets. Funct Integr Genomics. 2018;18(6):701-7.

26. Du KT, Deng JQ, He XG, Liu ZP, Peng C, Zhang MS. MiR-214 Regulates the Human Hair Follicle Stem Cell Proliferation and Differentiation by Targeting EZH2 and Wnt/ $\beta$-Catenin Signaling Way In Vitro. Tissue Eng Regen Med. 2018;15(3):341-50

27. Li X, Wu Y, Xie F, Zhang F, Zhang S, Zhou J, Chen D, Liu A. MiR-339-5p negatively regulates loureirin A-induced hair follicle stem cell differentiation by targeting DLX5. Mol Med Rep. 2018;18(2):1279-86.

28. Zhu N, Huang K, Liu Y, Zhang H, Lin E, Zeng Y, Li H, Xu Y, Cai B, Yuan Y, Li Y, Lin C. MiR-195-5p Regulates Hair Follicle Inductivity of Dermal Papilla Cells by Suppressing Wnt/ $\beta$-Catenin Activation. Biomed Res Int. 2018;2018: 4924356.

29. Hoefert JE, Bjerke GA, Wang D, Yi R. The microRNA-200 family coordinately regulates cell adhesion and proliferation in hair morphogenesis. J Cell Biol. 2018;217(6):2185-204.

30. Bai $W L$, Dang $Y L$, Yin $R H$, Jiang $W Q$, Wang $Z Y$, Zhu $Y B$, Wang $S Q$, Zhao $Y Y$, Deng L, Luo GB, Yang SH. Differential Expression of microRNAs and their Regulatory Networks in Skin Tissue of Liaoning Cashmere Goat during Hair Follicle Cycles. Anim Biotechnol. 2016;27(2):104-12.

31. Yang WB, Li QQ, Su B, Yu M. Microrna-148b promotes proliferation of hair follicle cells by targeting nfat5. Front Agric Sci Eng. 2016:3(1):72 (In Chinese).

32. Wheeler BM, Heimberg AM, Moy VN, Sperling EA, Holstein TW, Heber S, Peterson KJ. The deep evolution of metazoan micrornas. Evol Dev. 2009; 11(1):50-68 
33. Wang WG, Zhan RS, Zhou JH, Wang JL, Chen SJ. MiR-10 targets NgR to modulate the proliferation of microglial cells and the secretion of inflammatory cytokines. Exp Mol Pathol. 2018;105(3):357-63.

34. Bi LX, Sun L, Jin ZL, Shen ZJ. MicroRNA-10a/b are regulators of myeloid differentiation and acute myeloid leukemia. Oncol Lett. 2018;15(4):5611-9.

35. Lin SL, Miller JD, Ying SY. Intronic microrna (mirna). Biomed Res Int. 2014; 2006(4):26818

36. Lim LP, Lau NC, Garrett EP, Grimson A, Schelter JM, Castle J, Bartel DP, Linsley PS, Johnson JM. Microarray analysis shows that some micrornas downregulate large numbers of target mrnas. Nature. 2005;433(7027):769-73.

37. Park GT, Morasso MI. Bone morphogenetic protein-2 (bmp-2) transactivates $\mathrm{d} l \times 3$ through smad 1 and smad4: alternative mode for $\mathrm{dl} \times 3$ induction in mouse keratinocytes. Nucleic Acids Res. 2002;30(2):515-22.

38. Wu JH, Zhang WG, Li JQ, Yan ZW. Expression of bmp4 in skin of different stages of hair follicle development in Inner Mongolia cashmere goat. Heilongjiang Anim Sci Vet Med. 2009;12:35-6 (In Chinese).

39. Bai WL, Dang YL, Wang JJ, Yin RH, Wang ZY, Zhu YB, Cong YY, Xue HL, Deng L, Guo D, Wang SQ, Yang SH. Molecular characterization, expression and methylation status analysis of BMP4 gene in skin tissue of Liaoning cashmere goat during hair follicle cycle. Genetica. 2016;144(4):456-67.

40. Su R, Li JQ, Zhang WG, Yin J, Zhao J, Chang ZL. Expression of bmp2 in the skin and hair follicle from different stage in Inner Mongolia cashmere goat. Sci Agric Sin. 2008;41(2):559-63 (In Chinese).

41. Song LL, Cui Y, Yu SJ, Liu PG, Zhang Q. Expression characteristics of bmp2, bmpr-ia and noggin in different stages of hair follicle in yak skin. Gen Comp Endocrinol. 2017:260:18-24.

42. Adly MA, Assaf HA, Hussein MR. Expression of bone morphogenetic protein7 in human scalp skin and hair follicles. Br J Dermatol. 2010;154(3):551-4.

43. Wang XJ, He JN, Chen M, Liu KD, Liu JF, Liu N. Expression of BMPR1B gene in skin and its association with wool traits in fine wool sheep. Chinese J Anim Sci. 2016;19:1-5 (In Chinese).

44. Li YT, Chen FY, Chu JC, Wu C, Li Y, Li H. MiR-148-3p inhibits growth of glioblastoma targeting DNA methyltransferase-1 (DNMT1). Oncol Res. 2019. https://doi.org/10.3727/096504019X15516966905337.

45. Feng F, Liu H, Chen AP, Xia QH, Zhao Y, Jin XB, Huang JJ. MiR-148-3p and miR-152-3p synergistically regulate prostate cancer progression via repressing KLF4. J Cell Biochem. 2019. https://doi.org/10.1002/jcb.28984.

46. Cao HY, Liu ZM, Wang R, Zhang XD, Yi WF, Nie GY, Yu Y, Wang GL, Zhu MT. MiR-148a suppresses human renal cell carcinoma malignancy by targeting AKT2. Oncol Rep. 2017;37(1):147-54.

47. Fan Q, Meng XR, Liang HW, Zhang HL, Liu XM, Li LF, Li W, Sun W, Zhang HY, Zen K, Zhang CY, Zhou Z, Chen X, Ba Y. MiR-10a inhibits cell proliferation and promotes cell apoptosis by targeting BCL6 in diffuse large B-cell lymphoma. Protein Cell. 2016;7(12):899-912.

48. Vaher H, Runnel T, Urgard E, Aab A, Carreras Badosa G, Maslovskaja J, Abram K, Raam L, Kaldvee B, Annilo T, Tkaczyk ER, Maimets T, Akdis CA, Kingo K, Rebane A. miR-10a-5p is increased in atopic dermatitis and has capacity to inhibit keratinocyte proliferation. Allergy. 2019. https://doi.org/10.1111/all.13849.

49. Tampe D, Zeisberg M. Potential approaches to reverse or repair renal fibrosis. Nat Rev Nephrol. 2014;10(4):226-37.

50. Livak KJ, Schmittgen TD. Analysis of relative gene expression data using real-time quantitative PCR and $2^{-\Delta \Delta C t}$ method. Methods. 2001;25:402-8.

\section{Publisher's Note}

Springer Nature remains neutral with regard to jurisdictional claims in published maps and institutional affiliations.

\section{Ready to submit your research? Choose BMC and benefit from:}

- fast, convenient online submission

- thorough peer review by experienced researchers in your field

- rapid publication on acceptance

- support for research data, including large and complex data types

- gold Open Access which fosters wider collaboration and increased citations

- maximum visibility for your research: over $100 \mathrm{M}$ website views per year

At BMC, research is always in progress.

Learn more biomedcentral.com/submissions 